\title{
PSYCHE
}

VOL. XXV1

JUNE, 1919

No. 3

\section{A PROPOSED NOMENCLATURE FOR THE PARTS OF THE POSTERIOR RESPIRATORY APPARATUS OF DIPTEROUS LARVE AND A MICRO-PROTRACTOR USEFUL IN THEIR DESCRIPTION. ${ }^{1}$}

\section{By C. L. Metcalf}

It has been pretty generally recognized that the most serviceable diagnostic character for the specific determination of Dipterous larvæ of certain families is the posterior respiratory apparatus, which varies endlessly in the different genera and species, but appears to be very constant within the species. So superior are the characteristics drawn from this part of the larva, that I regard most descriptions which omit consideration of them as practically worthless. For in most cases the general features of shape, color, etc., may be found to apply almost equally well to other species. The most available, absolutely diagnostic characters are to be found on the posterior stigmata.

This apparatus consists, in many species, of three pairs of spiracles, generally more or less elongate or linear, and a fourth pair of circular structures (usually present) referred to in literature as "buttons" or "circular plates." This respiratory organ varies in the different families, genera and species in height; in width; in extent of elevation above the surface of the segment which bears it; in the ornamentation of the interspiracular spaces (vide infra); in length and width of the slit-like spiracles, which may be straight, curved, sinuate or denticulate, and variously arranged with respect to the median line and to each other; in the presence or absence of the circular plate, its position and diameter; and in many other ways.

1 Contributions from the Entomological Laboratory of the Bussey Institution, Harvard University, No. 160 .

2 In those rarer cases (as $e . g$., Estris ovis) where the three pairs of spiracles appear to be wanting, only a part of the following characteristics will be found to be applicable. 
The need of a satisfactory and uniform nomenclature of these parts is evident. Mr. Nathan Banks, ${ }^{1}$ Mr. M. E. MacGregor, ${ }^{2}$ and Professor W. B. Herms, ${ }^{3}$ especially, have emphasized the value of these structures with reference to the larvæ concerned in myiasis; the writer ${ }^{4}$ has for several years been applying this method to the larvæ of Syrphidæ; and indeed many investigators in recent years, have recognized the necessity of figuring the stigmal plates of the larvæ described in a number of Dipterous families. I have no doubt that many of the groups of amphineustic larvæ can be specifically diagnosed in the same way. In the various publications touching on this subject a variety of terms have been used. It is with the hope of acquiring uniformity of terminology in the various groups and by subsequent investigators that $I$ have herein compiled and described such of these terms as have come to my attention. ${ }^{5}$

The spiracles, together with the adjacent surface of the segment which bears them are called the stigmal field. The right and left halves of the respiratory organ, which are especially heavily chitinized, are each called a stigmal plate. The diagnostic points of chief importance, so far as my observations have gone are as follows:

(1) Whether the stigmal plates are sessile on the caudal surface of the last segment, or stalked, i. e., elevated at the end of a shorter or longer (sometimes tremendously elongate) tube.

(2) Whether the two stigmal plates are contiguous or separated.

(3) If separated, the distance between the plates: the minimum transverse distance intervening. (MacGregor, Herms.)

(4) If stalked, or sessile and contiguous, the width of the posterior respiratory organ: the maximum transverse measurement from lateral margin of one stigmal plate to lateral margin of the other.

(5) If separated, the width of one stigmal plate may be more satis-

\footnotetext{
1 Banks, N., The structure of Certain Dipterous Larvæ with special reference to those in Human Foods, Bull. U. S. Dept. Agr. Tech. Ser. 22, Jan. 10, 1912.

2 MacGregor, M. E., The Posterior Stigmata of Dipterous Larvæ as a Diagnostic Character: with Especial Reference to the Larvæ Incriminated in Cases of Myiasis; In Parisitology, Vol. VII, No. 2, June 19, 1914, pp. 176-188, 3 ppl.

8 Herms, W. B., Medical and Veterinary Entomology, The Macmillan Co., 1915, pp. 259, 260.

- Metcalf, C. L., The Syrphidæ of Ohio, Ohio Biol. Sur. Vol. I, Bul. 1, June, 1913; Me. Agr. Exper. Sta. Bul. 253, Oct. 1916; and do Bul. 263, Oct. 1917.

- I am indebted to Professor Charles T. Brues for assistance with the literature on this subject.
} 
factorily used, and in this case the easiest measurement to make appears to be the maximum, strictly transverse diameter. ${ }^{1}$

(6) If stalked, the length of the posterior respiratory organ or tube: the elevation of the stigmal plates above the general surface of the segment which bears them.

(7) The height of the stigmal plate or respiratory organ: the maximum dorso-ventral (sometimes apparently cephalo-caudal) measurement.

(8) The presence or absence of the circular plate or button. (Banks.)

(9) The position of the button, whether on the circumference of the stigmal plate ("ring" of MacGregor) or within it. (MacGregor.)

(10) The diameter of the circular plate or button: a strictly transverse measurement through its center.

(11) The distance between the mesal margins of the two circular plates. $^{2}$

(12) The length of the slit-like spiracles.

(13) The width of the spiracles.

(14) The shape of the spiracles, which are for convenience of further description named dorsal, median and ventral. It is necessary to note that the several spiracles on the same stigmal plate may vary greatly in shape and it is often necessary to refer specifically to them. ${ }^{3}$ See figure 1 .

(15) The ornamentation of the stigmal plate with spines, tubercles,

\footnotetext{
1 Professor Herms (loc. cit.) has used "the diameter of the stigmal plate, the space occupied by one stigmal plate on a line drawn through the center of both; (2) length, when slits are absent, the space occupied by a plate on a line drawn dorso-ventrally through the center of the plate; or when slits are present the space occupied by a plate along a line drawn from the lower edge of button (or space if button is absent) through the longest slit (middle slit) to the margin of the plate; (3) width, along a line drawn at the middle of the plate at right angles to the length line." These are so defined as to be a little difficult to measure,--requiring an estimation of such features as "the center of the plate," and a line at right angles to another. They are to this extent apt to lead to error, and will, I believe, be adequately supplanted by the more readily determinable features suggested above in paragraphs 5 and 7.

2 MacGregor suggests measuring from center to center of buttons, which complicates the matter by necessitating an estimation of the central point of each plate. Point 11, in connection with point 10 will give the same result more easily.

8 MacGregor (loc. cit.) attempts to divide the forms of posterior stigmata into two main types: the schizotreme-type especially characterized by possessing three pairs of slit-like spiracles; and the ptychotreme-type, possessing instead "a convoluted chain" (e.g., Musca domestica. Stomoxys calcitrans, Hamatobia serrata, etc.). But he, himself, points out that there are usually two ("three," loc. cit., p. 181) breaks in the chain. I think there is no sound basis for such distinction. Both of these forms have three pairs of spiracles; the convoluted spiracle and the slit-like one are fundamentally homologous, differing only in shape; and all possible intermediate grades of convolution and complexity are to be found. In cases of very great complexity, it is true, the spiracles may run together so that it is difficult to determine the limits of each, but I believe such forms have the same origin.
} 
carinæ, simple, branched or plumose hairs, etc. This ornamentation arises usually between the spiracles, and for descriptive purposes, I have numbered these inter-spiracular spaces, 1, 2, 3, and 4, beginning with the one mediad of the dorsal spiracle. See figure 1.

(16) The nature of the delicate chitinous bars crossing the slit-like spiracles (MacGregor); a point.undoubtedly of very great importance, but in many species too difficult of determination to be practically useful.

(17) The nature of the chitinous ring surrounding the stigmal plate; whether heavy or light, complete or incomplete; the last condition usually associated with the absence of the button or circular plate (MacGregor).

The most casual student could not but note the great diversity in position of the slit-like spiracles with reference to each other and to the median line of the body. Banks uses in his synopsis of the groups (loc. cit., p. 15) such characters as "slits arranged radially," or "sub-parallel to each other" or "rather transverse to body." MacGregor mentions "the orientation of the stigmata with reference to the . . . longitudinal axis of the larva" and the position of the slits with respect to each other and to the median sagittal plane of the body.

But, so far as I am aware, no attempt has hitherto been made to use for specific description

(18) The accurately-measured angle of divergence between the several spiracles, and

(19) Their divergence from the median line.

However, from my observations in the Syrphidæ and myiasiscausing species, I am convinced that much more can profitably be made of these points; and in the case of very closely related species, I believe this may at times prove to be the only reliable means of separation. These characters are, of course, available only in those cases where the spiracles are straight, or nearly so, so that their main longitudinal axis is readily determinable.

I was much surprised, when I conceived the notion of using this method of description, that I was unable to find anywhere on the market the apparatus by which such angular measurements could readily be made under the microscope. I finally designed a micro-protractor, ${ }^{1}$ for use in the ocular of the microscope, by means

\footnotetext{
1 Made by The Bausch \& Lomb Optical Co., Rochester, N. Y., who guaranteed its accuracy to within half a degree.
} 
of which it is very easy to gauge the angle of divergence of these parts. The micro-protractor (see figure 2) is a simple glass disk, $21 \mathrm{~mm}$. in diameter, ruled in angles so designed and arranged that by using different combinations of adjacent larger and smaller angles as indicated by the concentric lines in figure 2 , it is possible to measure very accurately any angle from $5^{\circ}$ to $360^{\circ}$ by $5^{\circ}$ intervals. Even single degrees of divergence may be estimated with considerable accuracy by this method.

In order to use these points it is only necessary to place the quiescent (killed or paralyzed) larva or the puparium under the microscope in such position that the plane of the stigmal plates is perpendicular to the axis of vision. The ocular with the microprotractor resting on its diaphragm is then revolved until some combination of its measured angles exactly coincides with the angle of divergence of the spiracles to be measured. ${ }^{1}$

The amount of divergence of the dorsal spiracles from each other I have called angle $A$ (See figure 1). In cases where the two stigmal plates are widely separated it may be easier to measure the divergence of either dorsal spiracle from the median line and this may be designated $\frac{\text { angle } A}{2}$. The amount of divergence between the dorsal and median spiracles on either side is angle $B$ : that between the median and ventral spiracles on either side is angle $C$; and that of the right and left ventral spiracles from each other is angle $D$. Here again the divergence of a ventral spiracle from the median line may be designated $\frac{\text { angle } D}{2}$. In all cases where the outer (peripheral) ends of two spiracles are closer together than their inner (central) ends, the fact is indicated by designating the corresponding angle a minus one. This is often the case with angles $\boldsymbol{A}$ and $D$ in the Syrphidæ.

In addition to its use as described above, I believe the microprotractor may prove useful to biologists in many lines of work where it is desired to measure the angles of microscopic objects.

\footnotetext{
1 Whenever it is possible to do so, much better results will be achieved by preparing the stigmal plates with 10 per cent KOH solution, as described by MacGregor and Herms in the papers cited above.
} 


\section{Explanation of Plate I.}

Fig. 1. Diagrammatic figure of the posterior respiratory organ of a dipterous larva indicating the several diagnostic characters. *Diameter of circular plate. 1, 2, 3, 4, first, second, third and fourth interspiracular spaces of left stigmal plate. I, II, III, dorsal, median and ventral slit-like spiracles, respectively, of right stigmal plate. IV, the left circular plate or "button."

Fig. 2. The micro-protractor showing arrangement of ruled angles. The various possible combinations from $5^{\circ}$ to $360^{\circ}$ indicated by the concentric lines.

\section{A PHYLOGENETIC STUDY OF THE MESOTHORACIC TERGA AND WING BASES IN HYMENOPTERA, NEUROPTERA, MECOPTERA, DIPTERA, TRICHOP- TERA AND LEPIDOPTERA. ${ }^{1}$}

\section{By G. C. Crampton, Рh.D.}

In several papers dealing with the phylogeny of insects, the Hymenoptera, Neuroptera, Mecoptera, Diptera, Siphonaptera, Trichoptera, Lepidoptera and their allies were grouped in a superorder called the "Panneuroptera." A portion of the evidence for such a grouping, based upon the study of the genitalia of males, has already been presented in Psyche, Vol. 25, p. 47, and in the Proc. Ent. Soc. Washington, Vol. 21; and in the present paper, I would briefly review the evidences of relationships indicated by the nature of the mesothoracic terga and wing bases in these insects. The terminology here adopted is that previously applied to the terga and wing bases of the Embiidæ, Plecoptera, Coleoptera and Dermaptera (Psyche, Vol. 25, p. 4), the Blattidæ, Plecoptera and Neuroptera (Jour. N. Y. Ent. Soc., Vol. 24, p. 1), the Orthoptera (Ann. Ent. Soc. America, Vol. 11, p. 347), and the Hymenoptera and Diptera (Jour. N. Y. Ent. Soc., Vol. 22, p. 248).

In the lower insects, the metathorax is subequal in size to the mesothorax, and in a few instances is even larger than the mesothorax. In the insects here considered, however, the mesothorax is usually the larger of the two, and since the metathorax becomes

\footnotetext{
${ }^{1}$ Contribution from the Entomological Laboratory of the Massachusetts Agricultural College, Amherst, Mass.
} 


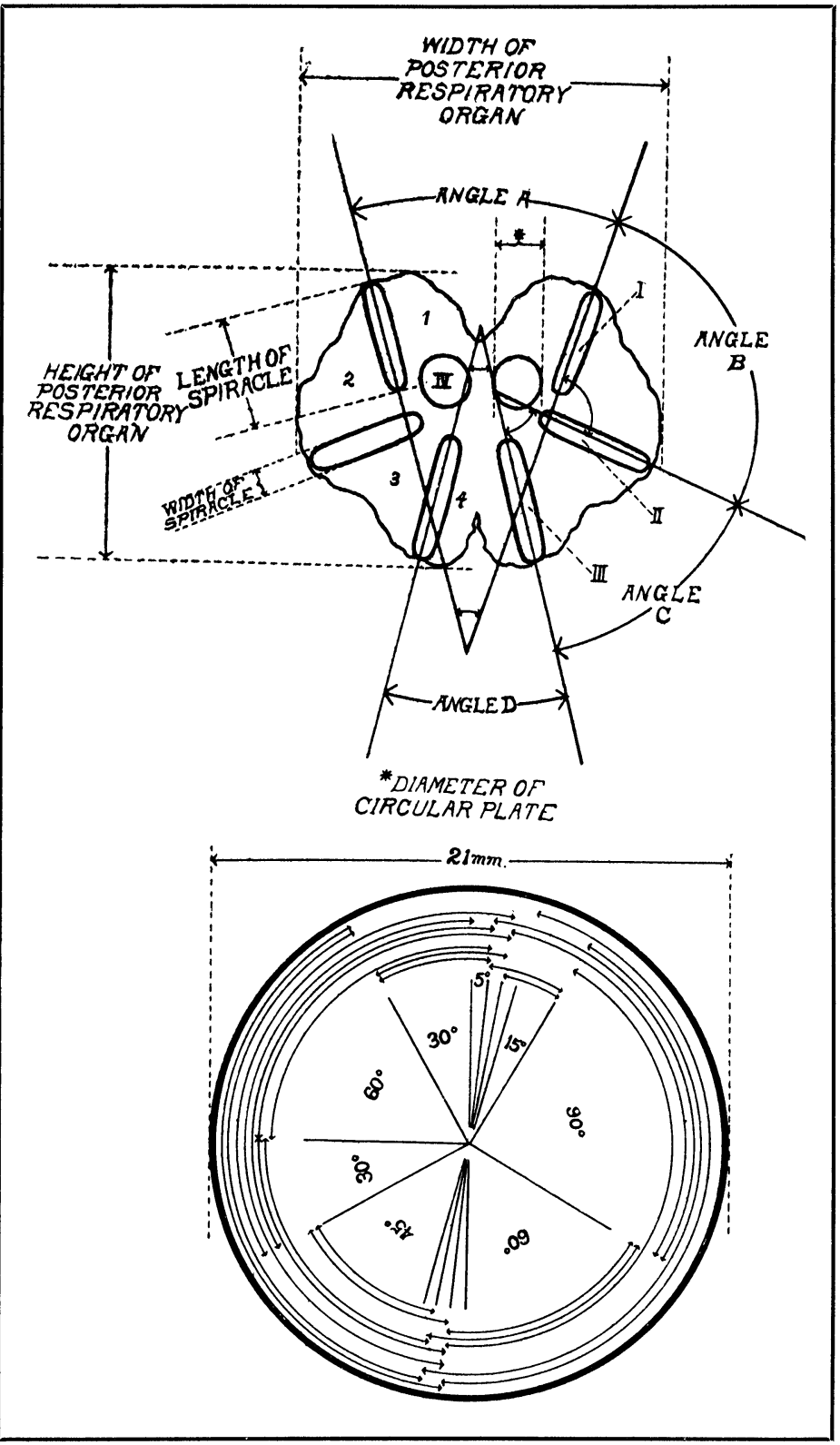

Metcalf-Respiratory Apparatus of Dipterous Larvæ. 

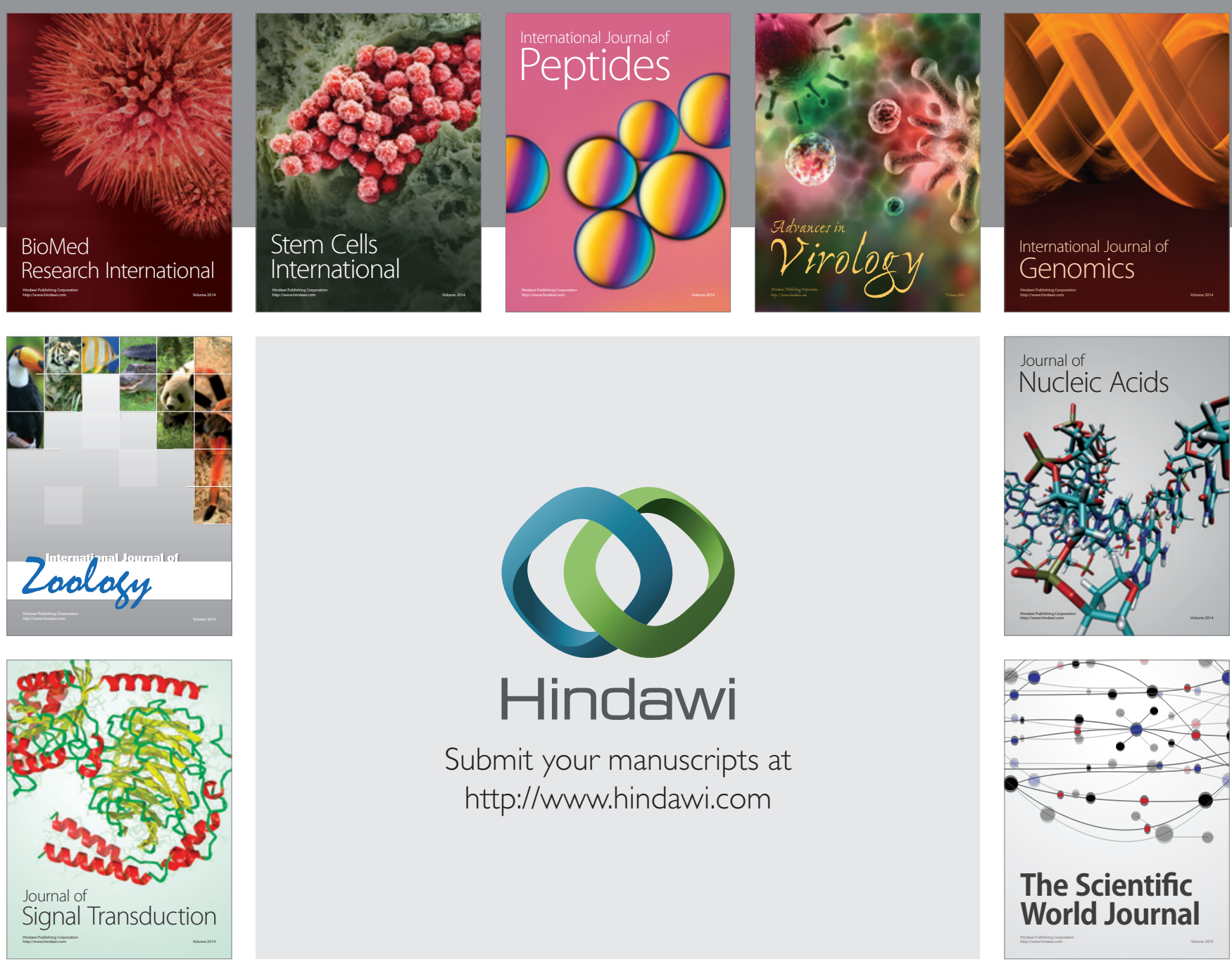

Submit your manuscripts at

http://www.hindawi.com
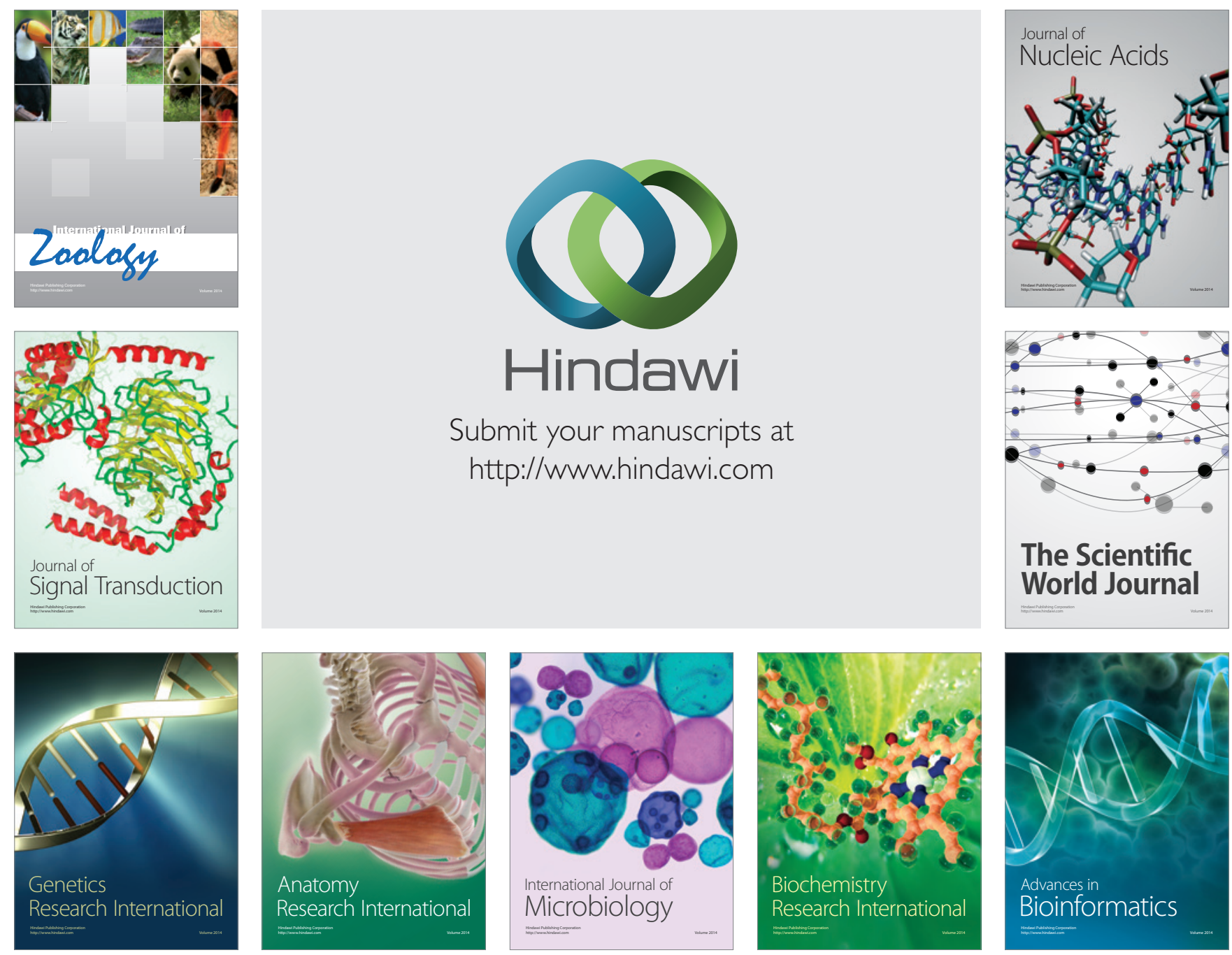

The Scientific World Journal
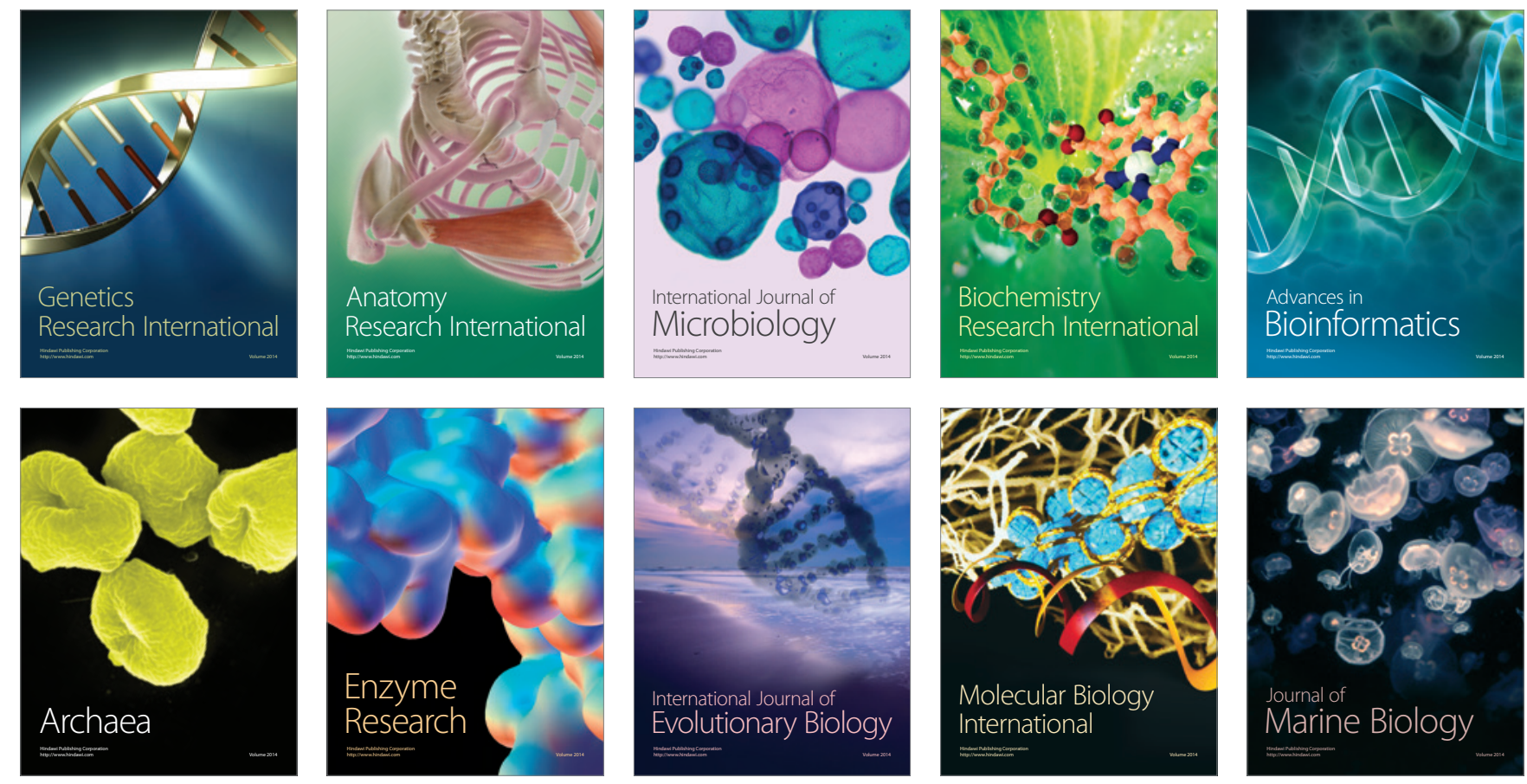